\section{O Atheneu Sergipense nos Tempos da Reforma Francisco Campos ${ }^{1}$}

Suely Cristina Silva Souza*

Resumo

O presente trabalho trilha a trajetória histórica do ensino secundário no interior do Atheneu Sergipense entre os anos de 1938 e 1943, anos em que respectivamente ocorreu em Sergipe à definitiva implementação da Reforma Francisco Campos e início da Reforma Capanema, segundo equiparação deliberada pelo Governo Federal. Para tanto, investigou-se alguns pontos das determinações do Decreto no. 7 de 14 de março de 1938, como: organização, admissão, matrícula e regime escolar. A Reforma Francisco Campos se fez presente no Atheneu Sergipense desde 1936, pelo menos na lei estadual, visto que na prática isso só aconteceu em 14 de março de 1938, através do Decreto no. 7, conforme designou o Interventor Federal no Estado de Sergipe ao despachar a criação do seu Regulamento Interno. Com efeito, percebi que os estudos secundários sergipanos apropriaram-se das ideias da Reforma Francisco Campos, ainda que tardiamente, acompanharam as deliberações da Divisão do Ensino Secundário. Portanto, a instalação dessa reforma em Sergipe aconteceu em substituição aos antigos Preparatórios pelos Cursos Complementares por meio da Portaria Ministerial de 17 de março de 1936, conforme equiparação ao Colégio Pedro II.

Palavras-chave: Reforma Francisco Campos, Atheneu Sergipense, Ensino secundário.

\footnotetext{
* Suely Cristina Silva Souza é Mestra em Educação pela Universidade Federal de Sergipe, licenciada em Matemática e Ciências Naturais pela Universidade Tiradentes e membro pesquisadora do Grupo de Pesquisa História das Disciplinas Escolares: história, ensino e aprendizagem (GPDEHEA/CNPq/UFS).

E-mail: suelycristinas@yahoo.com.br
}

The Sergipense Atheneu In The Time Of Reform Francisco Campos

\section{Abstract}

This paper track the historical trajectory of the reform of secondary education within the Atheneu Sergipense between the years 1938 and 1943, years which occurred respectively in Sergipe the final implementation of the Reform Francisco Campos and the second beginning of the Reformation Capanema deliberate assimilation by the Federal Government . To this end, we investigated some points of the determinations of Decree $n^{\circ} .7$ March 14, 1938, as: organization, admission, enrollment and school system. The Reformation Campos was present in Atheneu Sergipense since 1936, at least in state law, since in practice this only happened in March 14, 1938, through Decree $n^{\circ} .7$, as designated federal intervening in the State of Sergipe to ship the creation of its Rules of Procedure. Indeed, I found that secondary school Sergipe appropriated the ideas of the Reformation Francisco Campos, albeit belatedly followed the deliberations of the Division of Secondary Education. Therefore, the installation of this reform in Sergipe happened to replace the old Prep Supplemental Courses by Ministerial Decree of 17 March 1936, as equating the School Pedro II.

Keywords: Francisco Campos Reform, Atheneu Sergipense, secondary education. 


\section{Introdução}

As décadas de 1930 e 1940 ficaram bem conhecidas no cenário brasileiro pela implantação de duas Reformas educacionais que possibilitaram novos rumos à educação: a Reforma de Francisco Campos, no ano de 1931, e a de Gustavo Capanema em 1942.

Tais reformas respondiam às exigências político-ideológicas do momento, em meio à efervescência de diferentes ideais e concepções educacionais que se redefiniam no cenário brasileiro. Para tanto, naquela ocasião uma restauração no sistema educacional legitimaria e controlaria as intenções inovadoras do novo governo, além de representar um passo decisivo nas criações infraestruturais administrativas, necessárias à política centralizadora e intervencionista de Vargas.

Assim, o sistema de Interventorias controlava o poder central na política local. Para seu funcionamento os Executivos Estaduais passariam a ser chefiados por interventores diretamente subordinados a Vargas. As Assembléias Legislativas foram substituídas pelos departamentos administrativos, cujos membros também eram nomeados pelo Presidente da República e, em alguma medida, exerciam um domínio sobre os atos dos interventores. A esses departamentos cabiam a aprovação dos decretos-leis dos interventores, a aprovação e a fiscalização dos orçamentos estaduais, a avaliação do desempenho e da eficácia dos órgãos estaduais, e a apresentação de sugestões de mudança, entre outras tarefas (DANTAS, 1983).

Nessa perspectiva, a sociedade exigia da escola uma nova postura compatível com os emergentes princípios renovadores. Ao ensino secundário caberia a tarefa de preparar o adolescente para integrá-lo na sociedade, de acordo com as exigências do desenvolvimento industrial.

Frente às mudanças seria imprescindível desvincular o estudo da História de Sergipe do seu contexto nacional, principalmente no campo da Educação; é algo meramente difícil, haja vista a estreita correlação entre o que ocorria no Brasil e no território sergipano.
Até mesmo quando aborda-se uma reforma de ensino no espaço escolar, sem dúvida, é mister ter acesso à história do referido colégio, apontar algumas peculiaridades e desvendar sua atuação na educação. Desse modo trato, nessa parte do trabalho, das determinações prescritas pelo Decreto no. 7, de 14 de março de 1938, que regulava o Atheneu Sergipense segundo a Reforma Francisco Campos. Para tanto, também se tornaram fundamentais os estudos de Alves (2005) e Dantas (2004) que, entre outros aspectos, permitem apreender como se desenvolvia o ensino e a sociedade sergipana durante a década de 1930 e início dos anos 40.

Tal como aconteceu no Brasil, em Sergipe o projeto intervencionista se fez presente. Nomeado em 1930, o Tenente Augusto Maynard acompanhava o Presidente Vargas nas suas variadas transformações, mantendo-se solidário às suas orientações políticas. Possuidor de "amplo prestígio no meio urbano, especialmente junto aos setores populares da capital, empenhou-se em não perder contato com essa massa, que o cultuava como ídolo político e revolucionário" (ALMEIDA, 2009, p. 28).

$\mathrm{Na}$ área educacional Sergipe também seguiu as orientações nacionais, passando por transformações significativas, emergidas pelo ideário da Escola Nova. Conforme Dantas (2004, p. 117), o período varguista tinha como principal característica "a grande interferência do Estado, assumindo responsabilidades mais decisivas no setor educacional, revelando preocupações sociais [...]".

No discurso proferido pelo professor Rinaldo Oliveira, no ato da inauguração do retrato do Presidente Vargas, no Atheneu Sergipense, percebe-se a presença do ideário nacionalista na sociedade sergipana:

O entusiasmo é todo da Pátria neste momento, porque mais uma vez sua integridade política foi defendida e a nacionalidade triunfou levando ao desespero aqueles que tentaram outra vez perturbar a paz da família brasileira e inibir destruindo, matando, o reerguimento do Estado Novo [...] É necessária a repercussão forte desta manifestação cívica, para que se saiba que Sergipe, mantendo as tradições de bravura e heroísmo dos nordestinos, compartilha e le- 
vanta alto seu grito, irmanando-se aos de protesto que se fazem ouvir dos confins da nação, numa afirmação corajosa de solidariedade ao Presidente da República (DIÁRIO OFICIAL DO ESTADO DE SERGIPE, 24 de maio de 1938).

Incontestavelmente, a criação Atheneu Sergipense pela Diretoria Geral da Instrução Pública representou, nos anos de 1870, o evento cultural mais importante de Sergipe. $O$ referido colégio tinha por fim proporcionar à juventude sergipana o ensino secundário, além de ser pré-requisito de acesso aos cursos superiores por meio da admissão de determinado aluno nos Exames Preparatórios.

Tinha, pois, o Atheneu Sergipense, como finalidade do curso de Humanidades: proporcionar a instrução necessária para o acesso aos cursos superiores ministrando as cadeiras exigidas nos Exames Preparatórios, bem como formar indivíduos que pudessem desempenhar funções variadas na sociedade. Assumia, desse modo, não só o caráter propedêutico, mesmo porque havia ainda, na mesma casa o curso Normal, destinado à formação do quadro do magistério primário, iniciando a perspectiva de formação profissional do magistério sergipano (ALVES, 2005, p. 68).

A simultaneidade desses dois cursos constituía uma singularidade do Atheneu Sergipense, já que centralizar as aulas de Humanidades e as do curso Normal em um só lugar, "com professores lecionando ao mesmo tempo nos dois cursos, em horários estabelecidos para funcionarem as cadeiras em dias alternados", representava um avanço para a época (ALVES, 2005, p. 5).

Desde que fora instalado efetivamente, no dia 03 de fevereiro de 1871, o referido colégio também repercutiu na vida social aracajuana à medida que formava jovens, que, anos depois, assumiam funções e cargos de visibilidade local e nacional.

E que não diríamos nós porventura, se tivéssemos de recordar por miúdo os alunos desta casa, que em Sergipe ou fora dele derramaram a flux as cintilações de seu espírito [...] se falássemos de João Ribeiro, de Maximinio Maciel, de José Rodrigues da Costa Dória, de Gilberto Amado, de Manuel Bomfim, de Jackson de Fi- gueiredo, de Graco Cardoso, de Aníbal Freire, de Dias Barros, de Clodomir de Souza e Silva, de Esperidião Monteiro, de Felisbelo Freire, de Manuel dos Passos, de Carvalho Lima Junior, de Gamaliel Mendonça, de Gentil Tavares Mota, de Hunald Cardoso, de Barreto Filho, ou de José Calasans [...] (LIMA, 1945-1948, p. 28).

Quem por Sergipe passava não poderia deixar de visitar as instalações do Atheneu Sergipense. Era inevitável, na ocasião, não apresentar considerações do que se visualizava, até mesmo tecer comentários sobre os importantes destaques que foram revelados mediante sua cultura escolar.

Tivemos mesmo a sensação grata de que ingressamos em um templo de luz onde se culta, com religiosidade, o saber, pela ordem, silencio e alto coeficiente de educação demonstrado pelos discentes do Atheneu Pedro II (Jornal Correio de Aracaju, 19 de setembro de 1927, sem identificação de autoria).

Possuía uma doutra congregação, o Atheneu Pedro II vae dia a dia esclarecendo, instruindo, enfim alphabetizando a mocidade sadia e brilhante de Sergipe, Sergipe de Tobias Barreto, Sergipe de Fausto Cardoso, Sergipe de Hermes Fontes (Pereira Reis Junior, Livro de Visitas, 1931).

No período de 1871 a 1950, o Atheneu Sergipense sofreu mudanças em suas instalações. A instituição iniciou os trabalhos numa "casa oferecida pela Câmara Municipal, um local inadequado para as aulas". No dia 3 de dezembro de 1872, inaugurou-se um novo prédio na Praça da Conceição, hoje denominada de Praça Olimpio Campos. Indícios comprovam sua instalação na Rua de Boquim, por volta de 1899. "Em 13 de agosto de 1926 o Atheneu mudou-se para a Avenida Ivo do Prado". No ano de 1950, o colégio instalou-se na Praça Graccho Cardoso, permanecendo até os dias atuais. Em qualquer lugar sua localização sempre permaneceu na região central de Aracaju, "a vista da sociedade e próximo aos demais edifícios de destaques" (ALVES, 2005, p. 48-49).

Ainda, nas palavras de Alves (2005), esse estabelecimento de ensino modificou sua nomenclatura ao longo dos anos: 
Atheneu Sergipense (1870), Lyceu Secundário de Sergipe (1881), Escola Normal de Dois Graus (1882), Atheneu Sergipense (1890), Atheneu Pedro II (1925), Ateneu Sergipense (1938), Colégio de Sergipe (1942), Colégio Estadual de Sergipe (1943), Colégio Estadual Atheneu Sergipense (1970), e atualmente Centro de Excelência Colégio Atheneu Sergipense (desde 2003) (ALVES, 2005, p. 6).

Contudo, nesta dissertação o estudo do Atheneu Sergipense limitou-se entre 1938 e 1943, anos em que, respectivamente, ocorreram, em Sergipe, a definitiva implementação da Reforma Francisco Campos e o início da Reforma de Capanema, segundo equiparação deliberada pelo Governo Federal. Para tanto, investigou-se alguns pontos do documento que regulava a referida instituição, como: organização, admissão, matrícula e regime escolar, todos articulados com as fontes institucionais.

Assim, dividi essa parte da pesquisa em três tópicos. $\mathrm{O}$ primeiro tópico trata do percurso histórico da Reforma Francisco Campos no Atheneu Sergipense, desde seus primeiros indícios até sua implementação, mediante Regulamento Interno. Ainda aqui, motivada pela curiosidade de distinguir a ação de cada agente administrativo, busquei entender suas distintas funções quando, muitas vezes, durante a investigação dos documentos escolares faziam-se presentes.

O segundo tópico descreve o ingresso dos alunos nesse estabelecimento de ensino trilhando seus caminhos desde o processo de admissão até a matrícula, detalhando as determinações exigidas. $E$, por fim, o terceiro tópico narra os instrumentos que regularam aquela instituição, conforme os preceitos da ordem durante o cotidiano escolar.

\section{A trajetória histórica da Reforma Francisco Campos no interior do Atheneu Sergipense}

O Atheneu Sergipense não ficou à margem das questões políticas presentes no país. As transformações ocorridas no Brasil e em Sergipe, embora nem sempre paralelas, atingiram este estabelecimento de ensino. Logo, as reformas empreendidas no governo Vargas também foram sentidas. Isso pode ser verificado nos registros do próprio colégio, uma vez que é notável a mobilização e preocupação em adequá-lo às novas normas de ensino; verificado por meio da proposta aludida pelo professor Gentil Tavares, quando sugere que seja reformado o Regulamento Interno vigente na instituição por estar em desacordo com a atual legislação educacional de ensino secundário, cuja redação se encontra escrita no Livro de Ata da Congregação. Durante uma reunião:

[...] O professor Gentil Tavares propõe, depois de fazer varias ponderações, que seja reformado o actual regulamento do Atheneu em vista ter sido feito na vigência da Lei federal n. 16.782A, de 1926 e de achar-se em diversos pontos em desacordo com o que preceitua a actual reforma do ensino secundário. O sr. Presidente e demais professores presentes, ficou de accordo com a referida proposta ficando resolvido que em outra reunião se trataria mais circunstanciadamente do assumpto (Ata da Congregação de 05 de abril de 1937).

As informações contidas no trecho anterior nos remeteram ao seguinte questionamento: Como teria, efetivamente, sido instalada a Reforma Francisco Campos no Atheneu Sergipense?

Desde os anos de 1926, o ensino do Atheneu Sergipense se regulamentava por meio do Decreto $n^{\circ}$. 940, de 2 de julho de 1926 e atendia as determinações do Art.4\%, letra d, da Lei Federal nº. 938, de 21 de novembro de 1925, que tinha por fim moldar o ensino ministrado no Atheneu Pedro II, de acordo com o Colégio Pedro II.

Nesse período o Atheneu Sergipense denominava-se Atheneu Pedro II, conforme o Decreto no. 911, de 2 de dezembro de 1925, em homenagem ao centenário natalício de D. Pedro II. Segundo Alves (2005), desde 1899 essa instituição funcionava"na Rua de Boquim, no trecho da Atual Praça Camerino" (ALVES, 2005, p. 49).

Nos documentos investigados, os primeiros vestígios da Reforma Francisco Campos em Sergipe se reportam à Lei no. 40, de 18 de novembro de 1936, que "institui o Curso 
Complementar no Atheneu Pedro II, a gratificação por hora suplementar no Curso fundamental, cria o cargo de chefe de disciplina e dá outras providencias" (Lei no. 40, 18 de novembro de 1936).

Sancionada pelo Governador Eronides Ferreira de Carvalho e decretada pela Assembléia Legislativa do Estado de Sergipe, a referida lei determinava a implementação no Atheneu Pedro II, do Curso Complementar pelo período de dois anos, de acordo com o Decreto Federal no. 21.241, de 4 de abril de 1932. Assim, o estabelecimento de ensino obedeceria, para sua organização, às instruções expedidas pelo Ministério da Educação e Saúde Pública como: regime escolar, processo didático, distribuição, seriação, número de disciplinas e fiscalização.

Como se vê, a Reforma Francisco Campos se fez presente no ensino secundário do Atheneu Sergipense desde 1936, pelo menos na Lei Estadual, visto que na prática isso só aconteceu no dia 14 de Março de 1938, através do Decreto $n^{\circ} .7$, conforme decretado pelo Interventor Federal no Estado de Sergipe e de acordo com o Regulamento Interno da instituição estudada.

Nesta época, o colégio localizava-se na Avenida Ivo do Prado e denominava-se Ateneu Sergipense, conforme o Decreto $n^{\circ} .5$, de 16 de fevereiro de 1938, tornando sem efeito o Decreto no. 911, de 2 de dezembro de 1925. A referida designação atendia ao ofício expedido por Euclides Roxo, ordenando ao diretor do Atheneu Sergipense a mudança de nomenclatura, cuja determinação foi aceita de imediato, segundo correspondência enviada ao inspetor federal.

Do sr. diretor do Atheneu Pedro II, data de hoje. - Por intermédio do V. excia. Faço chegar ao conhecimento do sr. dr. Inspetor Federal, o teor do seguinte telegrama recebido ontem da Divisão do Ensino Secundário do Rio: - Diretor do Atheneu Pedro II - Aracaju - Sergipe - Comunico-vos de ordem do senhor Ministro nome Pedro Il é uso exclusivo colégio padrão Capital da Republica, não podendo ser usado nenhum estabelecimento de ensino. Deveis, pois, providenciar urgente de nome desse estabelecimento. - Euclides Roxo, diretor da Divisão de Ensino Secundário.

- Diante do exposto neste despacho, lembro que o nome Pedro II fosse substituído pelo de Sergipense primitivo nome desta Casa de Ensino desde a sua fundação (DIÁRIO OFICIAL DO ESTADO DE SERGIPE, Ofícios recebidos, 16 de fevereiro de 1938).

Na sua organização o ensino secundário deveria ser mantido pelo Estado, equiparado ao Colégio Pedro II, e subordinado à legislação federal, mas dependente economicamente dos atos e determinações provindas do governo estadual.

\begin{abstract}
A legislação federal regulará os cursos e seus programas e seriação, a organização do quadro dos docentes, as bases do ensino, a inspeção e fiscalização dos trabalhos escolares, e providenciará sobre as modificações que á prática mostrar indispensáveis a eficiência e bôa marcha dos serviços, por meio de instruções e portarias expedidas pela Divisão do Ensino Secundário (DECRETO n. 7, de 14 de março de 1938).
\end{abstract}

Anualmente o Governo do Estado fixava o número de alunos, após ouvir a diretoria do colégio a fim de orientá-lo, bem como evitar o surgimento de mudanças pedagógicas e na higiene escolar. Esse quantitativo não poderia exceder a quarenta alunos, caso contrário seriam organizadas novas turmas de cada disciplina.

\footnotetext{
$\S 1^{\circ}$. Quando o excedente não der múltiplo exato de quarenta, os alunos serão distribuídos em numero equivalente por todas as turmas.

$\S 2^{\circ}$. O dispositivo do paragrafo anterior se estende ás turmas de línguas vivas, cada uma das quais terá vinte alunos.

$\S 3^{\circ}$. Para a composição da primeira turma, serão tomados, de preferencia, os alunos que melhores notas houverem alcançado na série anterior, ou nos exames de admissão, seguindo a ordem decrescente das notas obtidas a organização de outras turmas (Art. 30, Decreto no. 7, de 14 de março de 1938).
}

Facultado a estudantes de ambos os sexos, o ensino secundário do Atheneu Sergipense ofereceu à população dois cursos seriados: Fundamental e Complementar. Esses cursos, segundo o presente regulamento, 
deveriam seguir à risca os programas estabelecidos no Colégio Pedro II. Também ministrar-se-ia, na forma da lei, a instrução militar.

Ao longo do ano letivo ministravam-se exercícios físicos e aulas de Música; os dois seriam obrigatórios aos alunos das três séries do Curso fundamental. As aulas de Música tinham por objetivo compor os elementos constituintes do Canto Orfeônico. Os exercícios de Educação Física para as alunas seriam realizados em turmas e horários diferentes dos alunos.

A cada período de um ano o diretor do Atheneu Sergipense tinha por obrigação descrever todos os fatos importantes sucedidos no colégio. Durante a leitura desses registros muitas vezes perguntava-me sobre a importância e função de cada agente da administração, já que os mesmos sempre se faziam presentes a cada relatório enviado ao Secretário Geral do Estado.

Mais uma vez cabe-me a tarefa de relatar a V. Ex o que de mais importante ocorreu no ultimo período decorrido, no estabelecimento que se acha sob minha direcção, mercê da distincção e da confiança do Exm. Sr. Presidente do Estado. [...] Pessoal administrativo - É o do annexo $n^{\circ}$ 16 o pessoal da administração deste estabelecimento [...] (Correspondência expedida, Relatório, 10 de julho de 1930).

Afinal, quem fazia parte do corpo administrativo do Atheneu Sergipense no momento da Reforma Francisco Campos? Desde 1926 o corpo administrativo da instituição compunha-se de um diretor, um vice-diretor, um secretário, um escriturário-arquivista, um escriturário-bibliotecário, um porteiro contínuo, um bedel, quatro inspetores de alunos, uma inspetora de alunas e dois serventes, conforme os termos do Art. 225 do Regulamento Interno de 1926.

A partir do ano de 1936, com a criação do Curso Complementar ocorreu, no Atheneu Sergipense, um acúmulo de serviços fazendo com que houvesse a necessidade de alteração no quadro do pessoal, conforme o Decreto no. 58 , de 8 de março de 1938. Contudo, com o novo regulamento de 1938, a administração do colégio passou a ser constituída por: um diretor, um vice-diretor, um secretário, um escriturário-arquivista, um escriturário-tesoureiro, um escriturário-bibliotecário, um chefe de disciplina, seis inspetores de alunos, duas inspetoras de alunas, conservador dos gabinetes, datilógrafo, porteiro, dois serventes e dois encarregados, sendo um deles para o asseio e da cantina e outro para a vigilância do estádio.

O diretor e seu vice eram escolhidos e nomeados dentre os professores efetivos ou em disponibilidade pelo Governo do Estado. A direção do colégio estava sob coordenação do professor Joaquim Vieira Sobral, conforme Decreto de 31 de março de 1937, cuja notificação se encontra nas páginas do Diário Oficial do Estado de Sergipe de $1^{\circ}$ de abril do mesmo ano.

Nomeado pelo Governo do Estado para o cargo de diretor do Atheneu Sergipense desde 1935, Joaquim Vieira Sobral exerceu suas funções a partir do Decreto de 31 de agosto, conforme publicação registrada no Diário Oficial do Estado de Sergipe em $1^{\circ}$ de setembro do mesmo ano. Entre as atribuições, também competia ao diretor:

a) organizar o orçamento anual de acôrdo com os dispositivos regulamentares e as necessidades do serviço;

b) cumprir e fazer cumprir o Regulamento, o orçamento aprovado pelo Governo e as leis ordinarias que interessem ao estabelecimento e fazer designações em materia de serviço;

c) ser o intermediario entre a Congregação e o Governo, em assuntos referentes ao ensino;

d) comunicar ao Governo a nomeação e demissão dos auxiliares do ensino;

e) propôr ao Governo a nomeação e a demissão dos professores interinos e designar substitutos; f) nomear e demitir os empregados subalternos tais como serventes, encarregados do asseio e da cantina e da vigilância do Estádio;

g) velar pelo fiel cumprimento dos deveres dos funcionarios administrativos e empregados subalternos e aplicar-lhes, salvo ao vice-diretor, as penas regulamentares;

h) verificar a assiduidade dos membros do corpo docente e a execução dos programas, aplicando as penas regulamentares, ou propondo ao Go- 
verno, segundo o caso, a aplicação dessas penas; i) convocar as sessões da Congregação, presidi-las e suspende-las quando necessário;

j) manter no estabelecimento rigorosa disciplina, aplicando as penas regulamentares;

k) organizar o horario das aulas, consoante o interesse do ensino;

l) tomar conhecimento dos recursos dos estudantes contra atos dos professores, ou funcionarios administrativos;

m) representar o Ateneu perante as autoridades constituídas ou designar representante em todo áto que justifique representação;

n) rubricar os livros da escrituração do ateneu ou dar autorização ao secretario para fazê-lo;

o) exercer a inspeção imediata do ensino e dos exames;

p) dar instrução, nos casos omissos, para os serviços do Ateneu de acordo com a legislação federal sobre o ensino secundário;

q) tomar, nos casos graves e urgentes, as medidas que forem indicadas pelas circunstancias, embora não previstas neste Regulamento, dando imediata conta ao governo do Estado;

r) declarar justificadas as faltas de comparecimento dos professores e funcionarios, que não exerceram de oito em cada mês, e a qualquer deles abonar, a seu juízo, até três faltas mensais; s) assinar as folhas de pagamento e remetê-las ao Governo;

t) prorrogar as horas do expediente, para os funcionarios administrativos e empregados subalternos, pelo tempo que for necessário ao serviço; u) apresentar ao Governo, anualmente, relatório de quanto ocorreu, no estabelecimento, a respeito do ensino, da disciplina, da ordem, da observância das leis e do orçamento [...] (Art. 160, Decreto nº. 7, de 14 de março de 1938).

Já o vice-diretor substituía o diretor nas suas faltas e impedimentos, auxiliava-o nos serviços do Atheneu, além de exercer as demais funções inerentes ao cargo. Também deliberava provisoriamente sobre quaisquer questões urgentes atribuídas ao diretor, porém seria preciso notificá-lo de todos os atos excetuados para uma resolução definitiva. Na falta do vice-diretor, o professor catedrático mais antigo o substituiria.
Nomeado pelo Governo, o cargo de secretário se destinava ao cidadão de reconhecida competência. Todos os seus atos estavam submetidos à fiscalização do diretor, mas sob suas ordens ficariam os escriturários, datilógrafo, os serventes e demais empregados subalternos. Segundo o Regimento, entre outras seriam suas atribuições:
a) organizar a escrituração do estabelecimento;
b) redigir e fazer expedir a correspondencia, in- clusive os convites para sessões da Congregação; c) superintender o serviço da secretaria, de que é chefe natural, fazendo a distribuição do servi- ço pelos auxiliares;
d) comparecer ás sessões da Congregação, das quais lavrará as atas;
e) lavrar os termos de penas do pessoal do instituto; [...] (Art. 164, Decreto no. 7, de 14 de março de 1938).

Como foi dito, incumbia-se ao escriturário-arquivista e escriturário-tesoureiro os serviços atribuídos pelo secretário. Embora, também competisse ao primeiro funcionário a guarda de documentos enviados pela secretaria ao arquivo e extrair certidões de registros a ele confiados. O segundo tinha a responsabilidade de guardar as taxas dos exames e receber do Tesouro do Estado às importâncias das contas do expediente, assim como as gratificações de aulas suplementares.

O mesmo acontecia com o escriturário-bibliotecário, ainda que, o competisse:
a) conservar-se na biblioteca, enquanto es- tiver aberta;
b) cuidar da conservação das obras;
c) organizar os catalogos de três em três anos, segundo os processos mais aperfeiçoados, ou- vindo o diretor; [...]
h) apresentar anualmente ao diretor um quadro estatistico dos leitores das obras consultadas e das que deixarem de ser fornecidas por não existirem; outrosim, uma relação das obras que trimestralmente entrarem na biblioteca; i) manter a ordem e disciplina na biblioteca; j) fazer carimbar os livros da biblioteca (Art. 170, Decreto n. 7, de 14 de março de 1938). 
E o que competia ao chefe de disciplina? Além dos deveres gerais, prezava pela ordem geral dos alunos dentro ou nas imediações do estabelecimento, encaminhando ao diretor todos os fatos irregulares notificados, conforme o Art. 173 do Regimento Interno. Tinham como subordinados os inspetores de alunos.

As atribuições dos inspetores de alunos estavam de acordo com Art. 178 do mesmo Regimento, tendo em vista que, sua vigilância e firmeza assim como sua ponderação e cordialidade, dependia essencialmente da disciplina dos alunos. Para esse cargo, o candidato a vaga realizaria uma prova de competência constituída de um ditado de 15 a 20 linhas, da leitura de um trecho qualquer manuscrito e de exercícios de cálculo prático, com os números inteiros, frações ordinárias e decimais.

O porteiro, além do que lhe competia, recebia do escriturário-tesoureiro as quantias necessárias para as despesas de pronto pagamento, das quais prestava contas.

a) velar pela bôa ordem e disciplina da portaria; b) ter sob sua guarda as chaves do edifício e de todos os compartimentos dêste;

c) cuidar do asseio interno fiscalizado os serventes e encarregados desse serviço; [...] (Art. 180, Decreto $n^{\circ} .7$, de 14 de março de 1938).

O servente, sob pena de demissão, não poderia possuir nenhuma familiaridade com os alunos nem recebia ordens de qualquer funcionário, tampouco aceitava retribuição ou presentes. Percorria frequentemente saguões, escadas e salas a fim de manter a limpeza, bem como o serviço das instalações sanitárias.

Ao encarregado do asseio e da cantina cumpria a higiene da escada e a limpeza dos aparelhos sanitários e mictórios, com o auxílio do servente. Abria a cantina durante o expediente, mantendo-a em ordem sob um rigoroso cuidado com os utensílios. Por fim, ao encarregado do Estádio competia vigiar o campo e os aparelhos utilizados pelos alunos do Atheneu Sergipense durante as aulas de exercícios físicos.

No início da década de 40 do século XX, sob comissão, nomearam-se ao cargo de diretor do Atheneu Sergi- pense dois professores: Felte Bezerra e José Augusto da Rocha Lima. O primeiro assumiu a direção em 1941 por meio do Decreto de 14 de julho, mas no ano de 1942 solicitou exoneração à Interventoria Fiscal, que assim o fez por meio do Decreto de 25 de julho. Esse mesmo decreto empossou José Augusto da Rocha Lima à função.

Pelo Decreto n. 32, de 6 de maio de 1942, o Atheneu Sergipense passou a ser denominado de Colégio de Sergipe2, "atendendo ao que estabelece a Lei Orgânica do Ensino Secundário" (DIÁRIO OFICIAL DO ESTADO DE SERGIPE, expediente da Interventoria, 7 de maio de 1942). Tal fato pode ser verificado na escrita do telegrama expedido pela direção da Divisão de Ensino Secundário ao Inspetor Federal junto a esse estabelecimento.

\begin{abstract}
Comunico-vos novo regime curso secundário deve ser imediatamente adotado quatro primeiras séries acôrdo Decreto-Lei 4.245 e portaria Ministerial 97. Novas instruções seguirão breve. Sds. Lucia Magalhães, Diretora Divisão Ensino Secundário.

Em cumprimento ao art.5, $\S 2^{\circ}$ e ao art. $6^{\circ}$, do Decreto-Lei n. 4.244, de 9 de Abril de 1942, em combinação com o art. 1, do Decreto-Lei 4.245, da mesma data, a diretoria do Ateneu Sergipense avisa que, para todos os efeitos, este Estabelecimento passará a denominar-se, de agora em diante, Colégio de Sergipe (DIÁRIO OFICIAL DO ESTADO DE SERGIPE, 7 de maio de 1942).
\end{abstract}

Apesar da mudança de nome apontar os primeiros indícios da nova Lei que se instalava na instituição, sua total implementação foi constatada nas páginas do telegrama enviando pelo Ministro da Educação Gustavo Capanema, ao diretor do Colégio de Sergipe.

Comunico-vos que o estabelecimento de Ensino Secundário sob vossa direção está autorizado a funcionar, no ano de 1943, como Colégio. As matrículas na primeira e segunda série do Curso Clássico ou do Científico deverão realizar-se até o dia 14 deste mês (Gustavo Capanema, DIÁRIO OFICIAL DO ESTADO DE SERGIPE, 13 de março de 1943). 
Em suma, a instalação da Reforma Francisco Campos em Sergipe aconteceu devido à substituição do Curso Complementar aos antigos Preparatórios, de acordo com a Portaria Ministerial de 17 de março de 1936. Desse modo, a realização dos exames de admissão da 1 a série do Curso Complementar ocorreu no ano de 1937, fato que fato que será explicado no próximo tópico e que também corrobora com as análises de Rocha (2001) e Otone e Silva (2006) sobre as discussões da definitiva instalação dessa segunda etapa dos secundários em âmbito nacional ${ }^{3}$.

Quanto aos agentes administrativos, sua movimentação se fez presente dentro e fora do Atheneu Sergipense à medida que eram nomeados, substituídos e exonerados, algumas vezes por distinção intelectual, a serviço, motivos de doença ou até mesmo particulares.

Despacho ao oficio n. 58 do Ateneu Sergipense, de 16 do corrente- comunicando que, nessa data, professor Florentino Menezes, na qualidade de substituto legal do diretor daquele estabelecimento, assumiu o exercício desse cargo, em vista de ter o serventuario efetivo viajado até a cidade do Salvador, em comissão do Governo do Estado [...] (OFICIAL DO ESTADO DE SERGIPE, ofícios despachados, 19 de abril de 1938).

Como se vê, todos os agentes administrativos do Atheneu Sergipense possuíam sua importância e atribuições, fato que ao longo do estudo ficou evidenciado, principalmente quando articulei essas informações com os dados contidos nas páginas dos documentos institucionais; sem dúvida, foi possível perceber a presença desses agentes escolares durante a pesquisa.

\section{Admissão e Matrícula: os procedimentos de in- gresso no Atheneu Sergipense}

E a amavel presença do meu antigo professor de Francês, dr. Leandro Diniz de Faro Dantas, que me acompanha os passos nesta commovida visita da minha saudade, - concorre para completar esta generosa allusão: - o "Atheneu Pedro II" é o mesmo "Atheneu Sergipense", onde entrei há precisamente dezeseis annos para iniciar a incessante tarefa que ainda não findou nem é dado saber quando terminará [...] (João Passos Cabral, Livro de Visitas, 10 de maio de 1928) ${ }^{4}$.

No trecho anterior é notório o motivo de orgulho e saudade do ex-aluno João Passos Cabral ${ }^{5}$, durante sua visita ao Atheneu Sergipense. Desde aquela época, ingressar nesse estabelecimento de ensino seria trilhar os caminhos na busca de uma extraordinária formação intelectual e moral apreendidas nas matérias estudadas, nos compêndios lidos e no convívio com a administração, professores e alunos da instituição.

Como se fazia para ser um aluno do Atheneu Sergipense? Existia algum procedimento específico para entrar nessa escola? Afinal, o que realmente se fazia necessário para estudar no tão almejado colégio? Procurando respostas a essas e outras questões, o presente tópico procura esclarecê-las.

Como já foi dito, desde os anos de 1926 o ensino do Atheneu Sergipense se regulamentava por meio do Decreto $n^{\circ} .940$, de 2 de julho de 1926 e conforme essa lei "os pais, tutores ou encarregados dos matriculados deverão apresentar ao diretor do Atheneu Pedro II, de 7 a 15 março de cada ano, os requerimentos solicitando inscrição para o exame de admissão" (Art. 4', Decreto n. 940, de 2 de julho de 1926).

As inscrições para os exames de admissão seriam anunciadas no jornal oficial do estado, no período de 16 a 25 de fevereiro, mediante registro efetuado na secretaria do Atheneu Sergipense. Para isso, seria necessário entregar a seguinte documentação: identidade de pessoa, comprovada com carteira de identidade; prova de bom comportamento, passada pelos diretores ou professores da escola que o candidato houver frequentado ou de autoridade policial; atestado de não sofrer de moléstia contagiosa ou infectocontagiosa e de imunização contra a varíola; prova de pagamento da taxa respectiva, conforme os Arts. $5^{\circ}$ e $6^{\circ}$ do referido decreto.

Os exames de admissão seriam realizados em duas épocas, sendo os da primeira efetuados em dezembro, e os

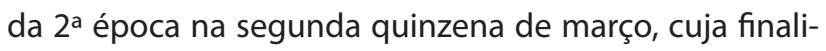
dade era verificar se o candidato estava "habilitado a em- 
preender com vantagem o estudo das matérias do curso secundário". Suas provas constariam de noções concretas acentuadamente objetivas, de Instrução Moral e Cívica, de Português, de Cálculo Aritmético, de Morfologia Geométrica, de Geografia e História Pátrias, de Ciências Físicas e Naturais e de Desenho, conforme programa do Departamento Nacional de Ensino (Art. 50, Decreto n. 940, de 2 de julho de 1926).

Após a realização das provas, iniciava-se o período de matrícula entre os dias 16 e 31 de março. Para tanto, os candidatos aprovados no $1^{\circ}$ ano deveriam comprovar idade mínima de 10 anos; apresentar certificado de aprovação no exame de admissão e pagamento de taxa de matrícula. Os pretendentes dos outros anos do curso juntariam ao seu requerimento a certidão de aprovação da série anterior e o recibo de pagamento da taxa respectiva.

Esse rito permaneceu no Atheneu Sergipense até a implementação do novo Regulamento Interno de 1938, que entre outras determinações modificou alguns pontos do processo de admissão e matrícula desse estabelecimento.

Ao ingressar no Atheneu Sergipense no ano de 1938, o candidato prestaria exame de admissão na $1^{\text {a }}$ série do Curso Fundamental na segunda semana de fevereiro, mediante inscrição realizada na primeira quinzena do mesmo mês, de acordo com requerimento firmado pelo pretendente ou representante legal.

$\S 1^{\circ}$. Contará do requerimento a idade, a filiação, a naturalidade e a residencia do candidato $\S 2^{\circ}$. O requerimento virá acompanhado de atestado de vacinação anti-variolica recente, de três anos no maximo, do recibo de pagamento da taxa de inscrição e de uma fotografia do candidato, de 3x4 (Art. 11, Decreto n. 7, de 14 de março de 1938).

Até o dia 30 de junho do ano pleiteado seria comprovada, mediante registro civil, a idade de 11 anos ao candidato que estivesse inscrito a fazer o exame de admissão em determinadas disciplinas no Atheneu Sergipense. Segundo o regimento interno, as matérias de Português, Matemática, Geografia, História Pátria e Ciências Físicas e Naturais versariam sobre: a) prova escrita de português e caligrafia, constando de ditado de 15 a 20 linhas do texto e da redação e descrição de uma das gravuras do "Quadro de Linguagem", ou outra qualquer de facil interpretação;

b) prova escrita de matematica, por meio de três questões sobre cálculo aritmetico elementar, relativo aos numeros inteiros, frações ordinarias e decimais;

c) prova oral de português, com leitura expressiva e análise léxica elementar de trêcho facil de escritor nacional contemporaneo;

d) prova oral de matemática, com emprego do cálculo prático, extensivo ao sistema metrico decimal;

e) prova oral de geografia, sobre nomenclatura e generalidades;

f) prova oral de historia patria, com argüição sobre os fátos gerais da história nacional, dispensas as minucias;

g) prova oral de ciencias físicas e naturais, sob o aspecto simplista das "lições de coisas" (Art. 15, Decreto no. 7, de 14 de março de 1938).

$\mathrm{Na}$ aplicação dos exames fazia-se presente uma comissão de três professores catedráticos, designados pelo diretor do Atheneu Sergipense e sujeitos a substituição em caso de não comparecimento. O examinador atribuía uma nota na matéria que avaliava, e, consequentemente, os candidatos que obtivessem pontuação inferior a 50 na prova escrita de Português ou de Matemática seriam eliminados. As notas dessas disciplinas contemplavam as médias das notas da prova escrita e da oral. Sendo assim, para aprovação no exame de admissão se fazia necessário alcançar, ao menos, o quociente de 50 .

No Atheneu Sergipense a procura pelos exames de admissão cresceu durante os cinco primeiros anos investigados, embora não fosse possível identificar, no ano de 1943, o número exato de alunos aprovados e reprovados. No entanto, nas fontes investigadas encontrei apenas dados referentes à seleção da segunda época desse concurso, notificados no Diário Oficial do Estado de Sergipe do dia 3 de março de 1943, conforme as informações do Quadro I. 


\begin{tabular}{|l|l|l|l|l|l|l|}
\hline Anos & 1938 & 1939 & 1940 & 1941 & 1942 & 1943 \\
\hline $\begin{array}{l}\text { Alunos } \\
\text { aprova- } \\
\text { dos }\end{array}$ & 16 & 49 & 78 & 87 & 202 & 62 \\
\hline $\begin{array}{l}\text { Alunos } \\
\text { reprova- } \\
\text { dos }\end{array}$ & 17 & - & 15 & 38 & 88 & 68 \\
\hline $\begin{array}{l}\text { Total de } \\
\text { inscritos }\end{array}$ & 33 & 49 & 93 & 125 & 294 & 130 \\
\hline
\end{tabular}

Quadro 01: Números de alunos inscritos nos exames de admissão do Atheneu Sergipense (1938-1943).

Fonte: Quadro elaborado a partir de Diários Oficiais do Estado de Sergipe localizados no Centro de Educação e Memória do Atheneu Sergipense (CEMAS).

De acordo com os dados, em relação ao ano de 1942, teria, o curso secundário do Atheneu Sergipense, diminuído o número de candidatos inscritos nos exames de admissão a partir do ano de 1943?

Durante a análise do Livro de matrículas da $1^{\text {a }}$ série do Curso Fundamental do ano de 1943, contabilizei um total de 209 alunos matriculados no Atheneu Sergipense, sendo que 53 deles eram repetentes. Os respectivos dados estavam distribuídos nas secções masculinas e femininas, apresentando 112 e 97 inscritos e um valor de 40 e 13 estudantes repetentes, respectivamente. Os referidos dados demonstraram que neste período ocorreu um crescimento significativo de jovens interessados pelos ensinamentos ministrados no curso secundário dessa instituição.

Por meio desses dados foi possível confirmar a presença dos ditames da Lei Orgânica do Ensino Secundário no Atheneu Sergipense, ao defender a não inclusão da co-educação em seu estabelecimento. Essa reforma determinava que nas escolas frequentadas por ambos os sexos, o ensino ocorreria em salas separadas para homens e mulheres, fato que pode ser comprovado nos registros das cadernetas do Atheneu Sergipense. Também, chegou-se à conclusão que houve um aumento gradativo no número de mulheres interessadas pelos estudos secundários da referida instituição.
Nessa época o curso estava dividido em dois ciclos: Ginasial e Colegial. O primeiro ciclo correspondia a um curso de formação geral, com duração de 4 anos. $O$ segundo correspondia a dois cursos paralelos, denominados de Clássico e Científico, cujo objetivo era consolidar, desenvolver e aprofundar os ensinamentos do Curso Ginasial por um período de 3 anos. A educação feminina foi uma das preocupações dessa nova lei, pois normatizava o papel da mulher como esposa e mãe, através do rol das disciplinas a serem ministradas, principalmente com a inclusão da Economia Doméstica nas $3^{\mathrm{a}}$ e $4^{\mathrm{a}}$ séries do Curso Ginasial (SOUZA, 2008).

Outro fato interessante localizado nas páginas dos Diários Oficiais do Estado de Sergipe discorreu sobre as mudanças ocorridas no programa dos exames de admissão do Atheneu Sergipense de uma época para outra. Ao analisar o pleito da primeira fase percebi que o mesmo não sofreu nenhuma modificação, contudo na segunda etapa do concurso houve alterações significativas.

A primeira época dos exames de admissão ocorreu mediante publicação do Edital no. 4, de 11 de novembro de 1942, cuja redação informava que de 20 a 30 do mesmo mês e ano ocorreriam inscrições para o ingresso na $1^{\text {a }}$ série do "curso ginasial, de acordo com o artigo 34, § $1{ }^{\circ}$ do Decreto-Lei Federal no. 4.244, de 9 de abril de 1942, combinado com o artigo 13 do regimento vigente desse colégio". As provas foram realizadas em 11 de dezembro de 1942, nas matérias de Português, Matemática, Geografia, História do Brasil e Ciências Físicas e Naturais (DIÁRIO OFICIAL DO ESTADO DE SERGIPE, 11 de novembro e 10 de dezembro de 1942).

Na segunda época dos exames de admissão, as inscrições ocorreram entre os dias $1^{\circ}$ a 10 de fevereiro de 1943 , cujas provas seriam realizadas na segunda quinzena do mesmo mês. As normas que regulamentavam o processo de ingresso ao Atheneu Sergipense permaneciam as mesmas, exceto quanto aos programas das matérias a serem cobradas, que sofreram algumas modificações. Essas alterações versavam sobre a supressão da disciplina Ciências Naturais, a retirada do sistema monetário brasileiro da prova de Matemática e a eliminação do assunto sobre os principais acidentes de Geografia Física 
dos continentes na Geografia, conforme Diário Oficial de Estado de Sergipe, em 6 de janeiro de 1943. Provavelmente, a diminuição de alguns conteúdos também tenha influenciado para o aumento do número de alunos admitidos no Atheneu Sergipense, durante as mudanças surgidas a partir do ano de 1943.

As matrículas dos Cursos Fundamental e Complementar se realizavam no período de $1^{\circ}$ a 14 de março de cada ano. Para tanto, a secretaria do Atheneu Sergipense publicava no Diário Oficial do Estado e nos jornais, por ordem do diretor, editais que informavam à sociedade sergipana.

No Diário Oficial do Estado, de fevereiro de 1937, numa publicação sobre matrícula no Atheneu Sergipense, verifiquei que até esse ano o colégio seguia as deliberações da Lei $n^{\circ}$. 40, de 18 de novembro de 1936. Segundo essa circular, os dias para matrícula naquela instituição se dividiam da seguinte maneira:

\section{Edital N. 6}

Matricula do curso fundamental

De ordem do sr. director scientifico aos interessados que de $1^{\circ}$ a 15 de março acham-se abertas nesta secretaria as matriculas para o curso fundamental [...]

Edital N. 7

Matricula do curso complementar

De ordem do sr. director scientifico aos interessados que de $8^{\circ}$ a 15 de março acham-se abertas nesta secretaria as matriculas para as três secções do curso complementar (ENGENHARIA, MEDICINA E DIREITO) [...]

[...], tudo de acordo com a Lei Estadual numero 40, de 18 de novembro de 1936 (DIÁRIO OFICIAL DO ESTADO, Secretaria do Atheneu, 27 de fevereiro de 1937).

Assim, o período de matrícula do Atheneu Sergipense atendia as determinações da lei federal que organizava a Reforma Francisco Campos, por meio do Art. 26, que afirmava: "a matrícula no curso secundário será processada de $1^{\circ}$ a 14 de março" (BRASIL, 1932).
Para efetivação da matrícula os alunos apresentariam alguns documentos. No Curso Fundamental precisariam do certificado de habilitação no exame de admissão para primeira série e, nas demais séries, certificado de habilitação na série anterior, atestado de saúde e recibo do pagamento da taxa de matrícula.

Além do requerimento, para se matricular no Curso Complementar o aluno admitido na primeira série necessitaria do certificado dos exames da $5^{\text {a }}$ série e recibo de pagamento da primeira prestação da taxa de matrícula. Se na conclusão do Curso Fundamental o estabelecimento de ensino fosse equiparado ou submetido à inspeção preliminar ou permanente, adicionar-se-ia aos documentos: atestado de saúde, certidão de idade, atestado de vacina, carteira de identidade e guia de transferência. Assim, os alunos concludentes do ano de 1935, constituíram a primeira turma de alunos sujeita ao Curso Complementar do Atheneu Sergipense para o ano de 1936.

Contudo, na $2^{\text {a }}$ série do Curso Complementar o aluno juntaria para matrícula, em seu requerimento: certificados dos exames da $1^{\text {a }}$ série deste curso e recibo de pagamento da 1 a prestação da taxa de matrícula acompanhado de declaração escrita, pelos pais ou responsável, em papel selado e firma reconhecida, responsabilizando-se diretamente por qualquer dano ou prejuízo causado ao edifício, mobiliário e material dos gabinetes de Geografia, Comosgrafia, Física, Química, História Natural e da Biblioteca do estabelecimento.

Anualmente o aluno pagaria duas taxas: a de matrícula e a de frequência. Os filhos dos funcionários públicos ficavam isentos da taxa de matrícula. No Curso Fundamental as taxas eram cobradas em duas prestações e no Complementar em três. De acordo com o regulamento, a primeira parcela seria cobrada no ato da matrícula, ficando, as outras, agendadas. Mais uma vez, encontrei nos Diários Oficiais anúncios que comprovam essa passagem:

Edital N. 7

De ordem do sr. professor diretor deste estabelecimento cientifica-se aos interessados que, de 16 a 30 do corrente, a Secretaria fornece GUIAS 
para pagamento da $\mathbf{2}^{\mathrm{a}}$ prestação de matricula para o CURSO COMPLEMENTAR, de acordo com o estatuído no $\S 2^{\circ}$ do artigo 24 , do regulamento baixado com o decreto n.7, de 14 de março deste ano[...]

Edital N.11

De ordem do sr. Diretor e de acôrdo com o [...] regulamento vigente, cientifico aos alunos do Curso Complementar que o pagamento da $\mathbf{3}^{\mathbf{a}}$ prestação da taxa de matricula $(100 \$ 00)$ será feito de 16 a 31 de Outubro corrente (DIÁRIO OFICIAL, Secretaria do Ateneu Sergipense, 14 de junho e 5 de outubro de 1938, grifos nossos).

Só se permitia transferência de alunos para outros institutos de ensino secundário nos períodos de férias, "mediante guia expedida pelo estabelecimento de ensino em que esteja matriculado o aluno, e da qual constará minuciosa informação sobre a sua vida escolar" (Art. 32, Decreto $n^{\circ} .7$, de 14 de março de 1938). E, para os institutos congêneres, admitia-se, a qualquer época e em qualquer das séries do curso, estudantes filhos de militares ou funcionários públicos que por ordem de superiores estivessem condicionados a mudarem suas residências para outro estado do Brasil.

Desde que comprovada a validade dos certificados dos alunos estranhos ${ }^{6}$ ao estabelecimento, os mesmos efetuariam suas matrículas após autenticação expedida por cônsul brasileiro ou pelo representante diplomático do país.

Quando verificado o número de vagas abertas na $1^{\text {a }}$ série do Curso Fundamental, divulgava-se em edital uma lista de candidatos a serem matriculados no prazo de 20 a 25 de março do corrente ano, mediante ordem crescente da nota de aprovação do exame de admissão. E, na sua inexistência, também se publicava aviso, conforme trecho transcrito:

AVISO

De ordem do sr. diretor, previno a quem interessar possa, que estão encerradas definitivamente as matriculas para os Cursos Fundamental e Complementar, NÃO EXISTINDO MAIS VAGAS (DIÁRIO OFICIAL, Secretaria do Atheneu Sergipense, 11 de março de 1941).
Nos anos de 1943, com a implementação da Lei Orgânica, também era visível a preocupação dos dirigentes pela educação sergipana. Na correspondência expedida pelo Ministro Gustavo Capanema à diretoria do Atheneu Sergipense, percebeu-se sua ansiedade com o início das aulas daquele estabelecimento. $\mathrm{O}$ mesmo telegrama advertia que a administração do colégio deveria esclarecer a população quanto à escolha do curso, explicando à mesma que tanto o Curso Clássico como o Cientifico possuíam direitos iguais para o acesso ao ensino superior.

As aulas terão início no dia 15. Deveis esclarecer aos candidatos ou aos seus pais antes de fazerem a opção de que trata o artigo 35 da Lei Orgânica do Ensino Secundário, que o Curso Clássico e o Curso Científico conferem direitos iguais com relação ao ingresso no Ensino Superior e a preparação literária e científica tanto num como no outro é suficiente e adequada aos estudos universitários de qualquer modalidade. Estou certo que envidareis os maiores esforços para que a educação secundária no nosso País seja cada vez mais sólida e aprimorada (Gustavo Capanema, DIÁRIO OFICIAL DO ESTADO DE SERGIPE, 13 de março de 1943).

Bem diferente dos cursos ministrados na Reforma Francisco Campos, os Cursos Clássico e Científico "não seriam considerados dois rumos diferentes da vida escolar", como aconteceu como os Cursos Complementares (RIBEIRO, 2006, p. 38). Segundo as Exposições de Motivos, os dois cursos da Reforma de Capanema não seriam especializados com finalidades específicas para um determinado setor do ensino superior, os alunos continuariam seus estudos de forma aprofundada, mediante ensinamentos apreendidos no Curso Ginasial durante três anos (BRASIL, 2005).

As inscrições dos exames de admissão aconteceram entre os dias 23 e 30 de novembro de 1942. Conforme dados publicados no Diário Oficial, esse fato marcaria o início da"primeira série do curso Ginasial; de acôrdo com os artigos 34 e seu § primeiro do Decreto- Lei Federal nº. 4.244, de 9 de abril de 1942 [...] (DIÁRIO OFICIAL DO ESTADO DE SERGIPE, Secretaria do Colégio de Sergipe, 12 de novembro de 1943). 
No período de $1^{\circ}$ a 14 de março de 1943 foram abertas, no Colégio de Sergipe, as matrículas dos cursos Ginasial e Colegial, sendo que os primeiros dez dias se destinavam aos alunos aprovados nos exames de admissão, para renovação e aos ingressantes do Curso do Colégio. Os demais dias "a Diretoria reservou para os interessados de outros Ginásios, que desejem transferências, no caso de haver 'VAGAS'"' (DIÁRIO OFICIAL DO ESTADO DE SERGIPE, Secretaria do Colégio de Sergipe, 27 de fevereiro de 1943).

No ano de 1944, para conclusão do ensino secundário, os pais e os alunos estariam cientes que prestariam "exame oficial do conjunto das disciplinas do Curso Clássico ou do Curso Cientifico", de acordo com a Lei Orgânica de 1942 (Gustavo Capanema, DIÁRIO OFICIAL DO ESTADO DE SERGIPE, 13 de março de 1943). A partir daí nasce um novo momento na educação sergipana que, na oportunidade, não nos compete investigar.

\section{O cotidiano escolar do Atheneu Sergipense}

Desde sua fundação a instrução secundária do Atheneu Sergipense era uma preocupação constante dos governantes. Muitos deles estudaram nessa instituição, cursaram o superior em outros estados e por lá se estabeleceram. Mas, mesmo morando longe, quando retornavam a Sergipe traziam na sua bagagem lembranças dos antigos métodos educacionais aplicados na sua formação, fato que pode ser verificado no relato do Ministro do Supremo Tribunal, Heitor de Souza, registrado nas páginas de um jornal local durante sua passagem pelas dependências do colégio.

Na salutar orientação da minha estremecida terra, na efficiente direcção deste instituto e na sua profícua fiscalização eu vejo, com legítima ufania, a continuidade moral dos antigos processos de educação e de ensino a que devo os primórdios da minha formação intelectual e moral (Heitor de Souza, Jornal Correio de Aracaju, $1^{\circ}$ de março de 1928).

Para manter a ordem no Atheneu Sergipense, durante a Reforma Francisco Campos, seus dirigentes seguiam as orientações do Regimento Interno conforme as exigências da Divisão do Ensino Secundário. Suas atribuições norteavam o regime escolar dos dois cursos, cuja verificação ficou comprovada ao confrontar a Lei Estadual com as fontes institucionais.

O período letivo datava entre 15 de março e 30 de novembro. Cada aula continha uma duração de 50 minutos, intervalos de 10 minutos e vinte e oito horas de trabalho semanal. A frequência seria obrigatória, até mesmo nas horas reservadas para os exercícios de educação física, música e instrução militar. Os Cursos Fundamental e Complementar funcionavam em turnos distintos, sendo vedada a entrada de alunos de um dos cursos quando o outro estivesse funcionando.

Como avaliação os alunos efetuariam arguições e trabaIhos práticos, além de provas escritas parciais com notas graduadas de cinco em cinco pontos, de zero a cem. $\mathrm{O}$ professor de cada disciplina atribuía aos alunos uma nota pelo menos, na arguição ou trabalhos práticos, a partir do mês de abril. Em todos os meses esses trabaIhos seriam realizados até o quinto dia do mês seguinte.

Na segunda quinzena de maio, julho, setembro e novembro cada classe realizaria quatro provas escritas parciais. O aluno que não comparecesse a qualquer uma delas só a faria por meio de requerimento acompanhado de atestado médico, entregue no prazo de oito dias a partir da data do afastamento; aquele aluno que não justificasse a ausência receberia nota zero.

Concluída a apuração da média e verificado que freqüentou a três quartos, no mínimo, das aulas e exercícios obrigatórios da série, será promovido a série seguinte, ou aprovado na última série, o aluno que obtiver, concomitantemente, nota igual ou superior a 30 em cada disciplina e média aritmética igual ou superior a quarenta no conjunto das disciplinas da série (Art. 53, Decreto N. 7, de 14 de março de 1938).

Os exames eram processados em duas épocas: a primeira em dezembro e a segunda em março, segundo as leis federais e circulares deliberadas pela Divisão do Ensino Secundário. 
Conforme edital exposto no Diário Oficial, os alunos que estivessem em atraso de pagamento ou de quaisquer taxas com o Atheneu Sergipense, não poderiam prestar exames nem tampouco se matricular no estabelecimento.

[...] aviso aos alunos matriculados nas três secções do Curso Complementar, que não satisfazerem a $2^{\text {a }}$ prestação de matrícula, agora, não poderão prestar a segunda prova parcial, a realizar-se na $2^{\text {a }}$ quinzena do mês corrente (DIÁRIO OFICIAL DO ESTADO DE SERGIPE, Secretaria do Atheneu Sergipense, 2 de julho de 1938).

A diretoria do Atheneu Sergipense expedia os certificados de promoção e de conclusão do Curso Fundamental e Complementar. Estes certificados e os de exames de admissão estavam sujeitos a pagamento de taxas. Também observei que, em alguns casos os exames realizar-se-iam gratuitamente, conforme dados contidos num telegrama enviado pelo diretor da Divisão de Ensino Secundário, Euclides Roxo, ao Inspetor Federal do Atheneu Sergipense, Otaviano Vieira de Melo, deliberando impedimento na "cobrança da taxa de promoção ou inscrição de exames dos alunos do curso ginasial inspecionado" (Euclides Roxo, DIÁRIO OFICIAL DO ESTADO DE SERGIPE, 20 de novembro de 1938).

As férias dar-se-iam em dois períodos: o primeiro, de $1^{\circ} \mathrm{de}$ janeiro a 15 de março; e o segundo, de 16 a 30 do mês de junho. Os encerramentos das aulas não determinariam o início das férias, pois os docentes seriam obrigados a comparecerem até quando durassem os exames no Atheneu Sergipense, durante todo mês de dezembro ou por convite do diretor em cumprimento a atos relativos a exames, reuniões extraordinárias da Congregação, concursos e outras solenidades.

Durante as aulas e solenidades todos os alunos eram obrigados a usar uniformes segundo os modelos adotados pela diretoria, principalmente nas comemorações de conclusão de curso nas quais os alunos deveriam estar bem uniformizados para registrarem em foto esse momento.

Essa determinação se estendia aos lugares públicos e em reuniões, desde que não proporcionassem desrespeito ao Atheneu Sergipense. Contudo, o descaso pela uniformização, principalmente pelo descuido e desalinho, também impedia sua entrada ao colégio. Naquela época, estar bem uniformizado seria muito mais do que vestir o fardamento escolar imposto pela instituição, compreendia em:
a) trazer a cabeça coberta com o casquete, sem- pre que estiver em formatura e logares públicos; b) conservar a blusa completamente abotoada; c) usar o calçado limpo, nunca esquecendo o verdadeiro emprego dos colchetes, cadarços, atacadores, etc (Art. 71, Decreto no. 7, de 14 de março de 1938).

Os programas das disciplinas dos dois cursos obedeceriam às determinações do plano adotado pelo Colégio Pedro II. Facultava-se ao professor o direito de modificar o programa de sua disciplina, "dando aos pontos que o compõem a extensão que julgar conveniente, e alterar a ordem dele, respeitadas as linhas gerais, que os caracterizam, quanto aos assuntos e a sua limitação" (Art. 71, Decreto $n^{\circ} .7$, de 14 de março de 1938).

Principalmente nas primeiras séries de cada disciplina, o ensino pratico e objetivo será o motivo das preocupações didáticas do professor, deixando para as séries finais os temas de mais complexa e dificil compreensão, as generalizações indispensaveis e os desenvolvimentos teoricos a que a disciplina comportar (Art. 76, Decreto n. 7, de 14 de março de 1938).

Assim, o ensino no Atheneu Sergipense estava em conformidade com a Reforma Francisco Campos, pois segundo o regulamento:

O ensino deverá ser feito sob aspecto de sua utilização imediata nas multiplas atividades da vida presente, de modo que o aluno adquira os elementos culturais que the aumentem as probabilidades de êxito e permita-lhe mover-se com vantagem nos quadros das concorrencias sociais e economicas (Art. 77, Decreto no. 7, de 14 de março de 1938).

Esse ensino seria ministrado por meio de quadros, livros, entre outros objetos. O diálogo também consistia numa ferramenta importante, desde que inspecionado pelo professor; o mesmo ocorreria: entre o professor e os alunos e entre os próprios alunos. 


\section{Considerações}

Com efeito, percebi que todos os agentes administrativos do Atheneu possuíam sua importância e atribuições, fato que, ao longo do estudo ficou evidenciado. Principalmente quando articulei essas informações com os dados contidos nas páginas dos documentos institucionais, sem dúvida foi possível perceber a presença desses agentes escolares durante a pesquisa.

Quanto aos estudos secundários sergipanos, os mesmos apropriaram-se das ideias da Reforma Francisco Campos implementada no Colégio Pedro II, do Rio de Janeiro. A instalação dessa reforma em Sergipe aconteceu em substituição dos antigos Preparatórios pelos Cursos Complementares por meio da Portaria Ministerial de 17 de março de 1936.

Contudo, ainda que tardiamente, o Atheneu Sergipense seguiu os desígnios da Reforma Francisco Campos tornando legítimo o pensamento de Bourdieu (2005), ao afirmar que quando "moldados segundo o mesmo modelo, os espíritos assim modelados encontram-se predispostos a manter com os pares uma relação de comunicação imediata" (BOURDIEU, 2005, p. 206).

Dessa maneira, percebeu-se, ao longo da pesquisa, que o Atheneu Sergipense respeitava as determinações advindas da Divisão do Ensino Secundário, além de manter uma comunicação ativa com esse Departamento, através de correspondências.

\section{Notas}

${ }^{1}$ A escrita desse texto faz parte de uma pesquisa realizada no Núcleo de Pós-Graduação em Educação, da Universidade Federal de Sergipe, cujo estudo configurou a disciplina Matemática no Atheneu Sergipense frente à Reforma Francisco Campos a partir do financiamento da Fundação de Apoio à Pesquisa e à Inovação Tecnológica do Estado de Sergipe (FAPITEC/SE).
${ }^{2}$ Em 1942 a mudança de nomenclatura apontou os primeiros indícios da Reforma Capanema, pois sua definitiva instalação no Atheneu Sergipense ocorreu a partir de 1943. Entretanto, a pesquisa não localizou nenhuma legislação educacional sergipana que comprovasse a implantação da Reforma de Capanema no interior dessa instituição, apenas encontraram-se algumas publicações sobre o assunto nas páginas do Diário Oficial do Estado de Sergipe.

${ }^{3}$ Essas discussões podem ser consultadas em Souza (2011, p. 47).

${ }^{4}$ Apesar da transcrição acima pertencer a um período anterior ao estudado na pesquisa é significante, pois, as impressões dos visitantes esclarecem o processo de formação da mocidade sergipana.

${ }^{5}$ Nascido em 7 de agosto de 1887, na cidade de Aracaju, João Passos Cabral foi estudante do Atheneu Sergipense desde o ano 1912. Em 1916 prestou exames finais nas matérias do curso de Humanidades. Atuou profissionalmente na imprensa aracajuana e nos Correios do Estado, além de produzir artigos, poesias, romances e críticas para diversos jornais. Foi professor de Literatura da escola Normal Rui Barbosa. Faleceu no Rio de Janeiro, em 1950 (GUARANÁ, 1925).

${ }^{6}$ Denominação aplicada aos alunos que não eram matriculados no Atheneu Sergipense, mas que tinham interesse pelo estudo dessa instituição. Para seu ingresso, inscrever-se-iam nas vagas disponíveis nas diversas séries do Curso Fundamental e Complementar durante o período de matrícula.

\section{Referências}

ALMEIDA, Sayonara do Espírito Santo. A Reforma Gustavo Capanema: vislumbrada no currículo do Atheneu Sergipense (1940-1944). Monografia apresentada ao Departamento de História. Universidade Federal de Sergipe. São Cristóvão/SE, 2009.

ALVES, Eva Maria Siqueira. O Atheneu Sergipense: uma casa de educação literária segundo os planos de estudos (1870-1908). Tese de Doutorado, Programa de Estudos Pós-Graduados em Educação, História, Política, Sociedade. PUC/SP. São Paulo, 2005.

BOURDIEU, Pierre. A economia das trocas simbólicas. 6. ed., São Paulo: Perspectiva, 2005

BRASIL. DECRETO N. 21.241. Rio de Janeiro, 04 de abril de 1932: consolida as disposições sobre a organização do ensino secundário e deliberou outras providências. 
Disponível em:<< http://www.histedbr.fae.unicamp.br/>> acessado em 01/02/2009.

BRASIL. Decreto N. 4.244, de 9 de abril de 1942 - Exposição de motivos. Rio de Janeiro, $1^{\circ}$ de abril de 1942. In: CD Rom: A Matemática do Ginásio: livros didáticos e as reformas Campos e Capanema. São Paulo: GHEMAT, CD-ROM, 2004.

DANTAS, José lbarê Costa. História de Sergipe: República (1889-2000). Rio de Janeiro: Tempo Brasileiro, 2004.

. História de Sergipe: República (1889-2000). Rio de Janeiro: Tempo Brasileiro, 2004.

GUARANÁ, Manuel Armindo Cordeiro. Dicionário Bio-bibliográfico Sergipano. Rio de Janeiro: Pongetti, 1925.

LIMA, José Augusto da Rocha. Discurso pronunciado no salão da Congregação do Colégio estadual de Sergipe pelo professor José Augusto da Rocha Lima, a 15 de março de 1947, por ocasião do centenário do ensino secundário em Sergipe. In: Revista do IHGS. Aracaju: Livraria Regina Ltda, Vol. XIV, no. 19, 1945 a 1948, p. 21-30.

OTONE E SILVA, Maryneusa Cordeiro A Matemática do Curso Complementar da Reforma Francisco Campos. Dissertação (Mestrado em Educação Matemática). PUC/SP. São Paulo, 2006.

RIBEIRO, Denise Franco Capello. Dos cursos complementares aos cursos clássicos e científicos: a mudança na organização dos ensinos de matemática. Dissertação (Mestrado em Educação Matemática). PUC/SP, São Paulo, 2006.

ROCHA, José Lourenço da. A Matemática do curso secundário na Reforma Francisco Campos. Dissertação (Mestrado em Matemática). PUC/ RJ. Rio de Janeiro, 2001.

SOUZA, Rosa Fátima de. História da organização do trabalho escolar e do currículo no Século XX: (ensino primário e secundário no Brasil). São Paulo: Editora Cortez, 2008.

SOUZA, Suely Cristina Silva. Uma história da disciplina Matemática no Atheneu sergipense durante a ação da Reforma Francisco Campos (1938-1943). Dissertação (Mestrado em educação. Universidade Federal de Sergipe. São Cristóvão/SE, 2011.

Fontes Manuscritas

Livro de Atas da Congregação do Atheneu Sergipense (1916-1939)

Livro de correspondências expedidas (1929-1932)

Livro de Visitas (1916-1951)

Legislação: Decretos, Leis e Regulamentos

Decreto $n^{\circ}$. 911, de 02 de dezembro de 1925;

Decreto $n^{\circ}$. 940, de 02 de julho de 1926;

Lei ${ }^{\circ}$. 40, de 18 de novembro de 1936;

Decreto $n^{\circ} .5,16$ de fevereiro de 1938 ;

Decreto-Lei no. 58, de 08 de março de 1938;

Decreto $n^{\circ} .7,14$ de março de 1938.
Revistas, Folhetos, Fascículos

Diário Oficial do Estado de Sergipe (1938-1943);

Jornal Correio de Aracaju, 19 de setembro de 1927; Jornal Correio de Aracaju, 1º de março de 1928.
Recebido em 01/07/2011

Aprovado em 02/10/2011 
